\title{
SUPER-CONNECTED: HOW TECHNO TOURISM REDESIGNS OUR \\ LIVES THROUGH MEANINGFUL TRAVEL
}

\author{
Rakshha Kumari Karna \\ Harbin Institute of Technology, School of Management, P.R.China \\ Ye Qiang \\ Harbin Institute of Technology, School of Management, P.R.China \\ Arodh Lal Karn \\ Harbin Institute of Technology, School of Management, P.R.China
}

\begin{abstract}
The techno-tourism life brings together insights about innovative tourism and examines how travel life is influenced when social network structure like "Facebook" enters the picture. The end result is a landmark analysis of digital socialization and the knock of the internet and digital media across travel institutions. This research circumscribes the 'tourists-marketers facebook pages' of Nepal. Using archived online narratives from facebook page of travel-marketers (TMs), after the event of Nepal earthquake 2015, this study seeks to examine how techno-tourism redesigns lives through meaningful travel plus the coverage toward which event enthusiasts participate in chats of interactional causes. This study first of all dissects the intrinsic features of the facebook just like facebook pages exploitation by travel marketers during Nepal's earthquake disaster at district, zonal and state level. The study then offers some interesting insights for tourism marketers. It involves the statistical and mathematical model to observational and experimental datasets of their facebook posts and fans participation. This research drafts the importance of network science of super-connected digital voyagers, studying their sways, their point of views, their approaches of travel and their intensions for inspiring this style of travel feasible in requisites of work and money. As relationships are the foundation for social media sites; facebook is primarily used to raise awareness and create story telling. Hence this investigative study also has meaningful implications for public policy as well as super-connection as global impact. By adducing human race into one another's care, letting them to fathom commonalities, likewise endowing the resources by which they can super-connect one another, the digital media and World Wide Web chip-in greatly to the "techno-social life". This research is a great choice for general readers interested in this topic as well.
\end{abstract}

Keywords: Social media; Facebook; Tourism; Nepal

JEL code: D830, O310, O320 


\section{Background}

Social network structures play an essential meaning equally on the compulsion and on the contribution part of visiting the sights of interests permitting destinations to couple candidly with holidaymakers through diverse web dais as well as scrutinize plus respond on holidaymaker perceptions with speculations of endowments. Study so far has publicized that engaging innovatively with supporters via social media will present an ultimate dais for establishing durable equally lucrative relationships. Social media normally acknowledges to web applications that set aside for the user to post and share content. They are providing four most important promote i.e. (4C): conversation, cooperation, citizenry, and collective intelligence opportunities(Ketter, 2016). Shared media use for shared change can be well-off. In support of e-destinations the preeminent practices are acknowledged through the facilitate of a total theme study of vocations' web link showing up and weblog relevances plus height of implementation of technologies and applications (Ballings and Van den Poel, 2015). So far e-destination and social media branding of Nepalese destinations is concerned, a painstaking data of tourism in Nepal by the world travel and tourism council are stated in Figure 1. The country has a budding potential for tourism due to its geographical and cultural diversification. The geographical setting of Nepal appears to be both the reward and blight by the nature. At one point the lovely scenic magnificence entices scores of vacationer which boom the tourism related business of Nepal and it looks as if to be the gift of nature to Nepal. Nevertheless, at odds to it, the geographical setting (the Indian and Eurasian plates squeezing Nepal resulting earthquakes followed by blizzards and avalanches, landslides etc.) gives the impression to act like the blight of nature to Nepal. So, the tourism industry of Nepal seems to be bouncing to and from and up and down in this game of nature 


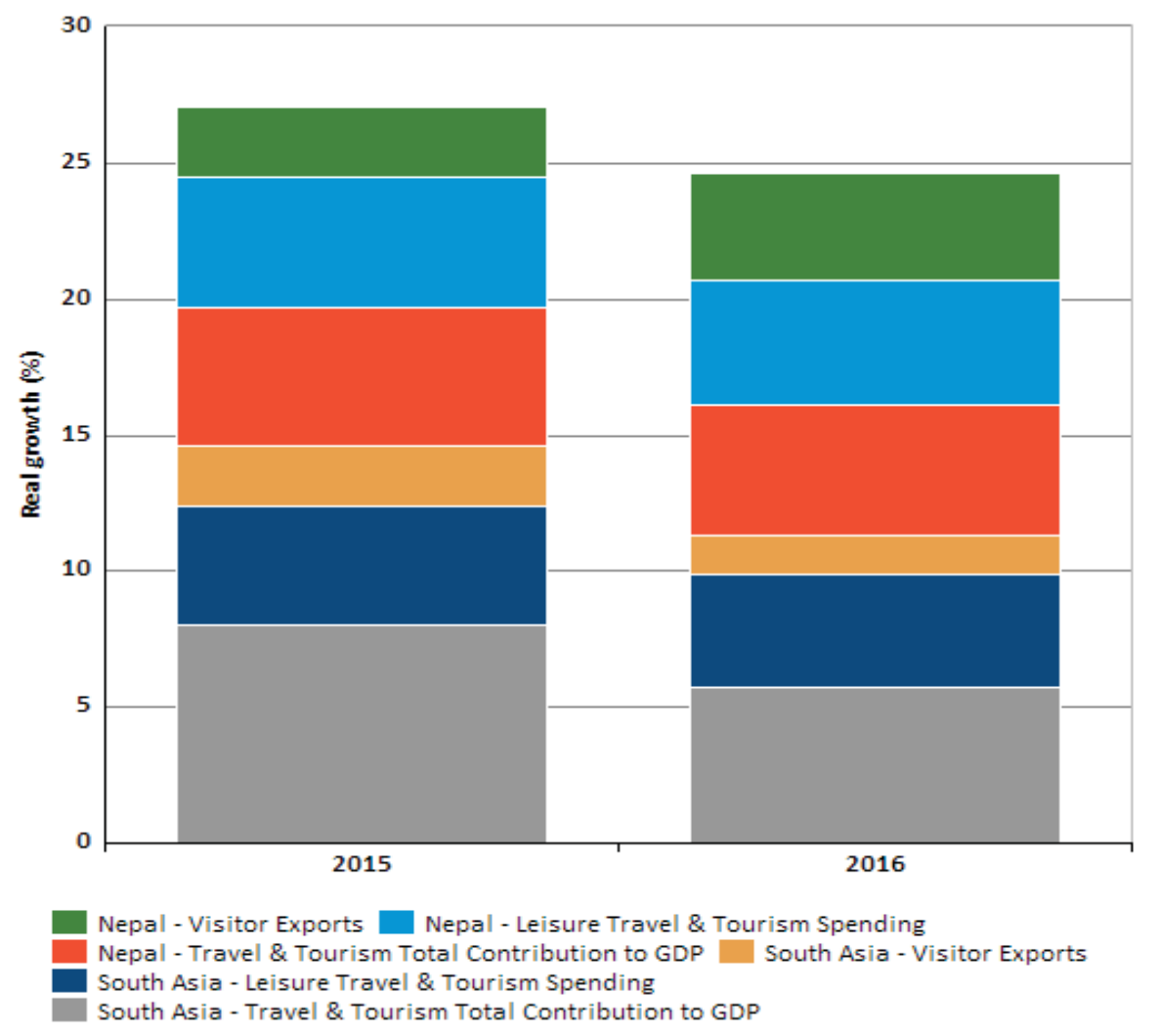

Figure 1 Nepal key facts. Source: (World Travel and Tourism Council, 2016)

The seismic activity in $25^{\text {th }}$ of April, 2015, measuring 7.8 in the Richter scale and its consequent after effects has unswervingly revealed its blow upon the whole nation. In the order of 9,000 inhabitants lost their lives and additional 22,000 people were wounded. The depressing ramification of the tragedy are apt to turn into a reduced figure of tourist arrivals over the next few years, cry off in tourist spending per day from USD 43 to USD 35, which will considerably influence revenues.

Social media knows how to augment world understanding of an issue. As a consequence, adopting the preeminent practices in restoring tourism back is a necessity where strategy of addressing to the concern will be requisite. Consequently away from the orthodox and inferior tourist circuits, e-tourism with voluntourism refers to voyages taken to destinations for the intention of supporting host communities of interest by pledging services that help in everyday life or relieve to disaster areas. At this juncture social media allows community get "super-connected" so to help each other and charity collection regardless of location, can be domestic or international, from any originating market and up to several days. In the course of the shifting from offline to online voyagers, the media and web-link presence of vocations are vital as electronic destinations give out display place where patrons can be motivated, search out all the information about a prospective voyage to a intended place and ultimately reserve the vacation (Leung, Xue et al., 2015). There is an urge to explore the efficacy of the entire 
e-touristy creation linking to vocation's integrated technologies and relevancies' sustaining the user's perceive (Jucan, Jucan et al., 2013). This piece of writing hopes that by working with the society, the investigation into new tools such as Facebook, and other social media can present a low expenditure and high impact promotion campaign which can grant very important finances for assistance across the board. This paper will first look at the subsequent statements concerning the employ of social media for communities revolutionize:

1. Social media is able to boost world understanding of an issue.

2. Social media allows public to assist each other and assistance collection in spite of location.

3. Social media use for social transform can be successful.

\section{Literature Review}

The literatures here tack on to the existing body of e-tourism research. Empirically-based researches look into TMs' online promotion as of equally an advanced and a vicenary standpoint (see, Hays, et al., 2013). Social media offers tourists of contemporary era with an unparalleled expansion in ways of conversation as well as interface. Facebook, as a leading public web linking display in the globe, be able to be used to demonstrate the substantial weight of online public networking super-connectedness on take a trip industry (see, Popesku and Pavlović, 2013). Voyage is an immense ingredient of facebook associates' dialogues as $\geq 43 \%$ of facebook fellow' partake in the inside story on where they pass through, $\geq 61 \%$ considers facebook friends viewpoint into their take a trip judgments while $\geq 80 \%$ trust the references of their relatives and associates ( see, Aspasia and Ourania, 2014). In the area of touristy and the associated areas under discussion of event tourism, events are presented as "open, themed involvement" ( see, Stalidis and Karapistolis, 2014). Reference (Schmidt and Baumgarth, 2014) initiated that events breed social assets amid their communities. Reference (see, Kavoura and Stavrianea, 2014). Clearly presents three ways into which events fabricate positive social principal. Reference (see, Kavoura, 2014) itemized the power of events to make possible the passage of social limits like intolerance and narrow-mindedness through constructive social exchanges. Events can furthermore produce elusive, social influences between their communities. Yet, there is a lot divergence over how to perfectly gauge elusive impacts. The intensification of social media possibly will grant an opportunity to resolve this canvass. This study uses facebook as means to look into in a social context provoked thought. Natural calamities are derailing on or after further manner of unusual incidents by their impetus, which is the condition of crisis and call for assistance, supporting hands or intonation of the factual, societal or ethnic facets of a selective embattled neighborhood ( see ,M. Mariani, Baggio et al., 2014). The latest tourism journalism has lectured to the function and utilize of online social platform in tourists' choice-making, plus in touristry maneuver along 
with administration (Bilgihan, Barreda et al., 2016). Whereas user-Centrica literatures have by and large paying attention on the exploit and brunt of social media in the investigate segment of travelers' scheduling course ( see, Dijkmans, Kerkhof et al., 2015) while provider-ignited researches have rigorous look on the endorsement, administration, as well as inquiries tasks ( see, Luo and Zhong, 2015). Online social platform is satisfying growingly importance as a tourist areas advertising means, furthermore consequently have to be successfully handled by TMs seeming to craft a maintainable spirited lead pro their sites inside the aggressive dome of international touristry (see, M. M. Mariani, Buhalis et al., 2014). The situation is all the more pertinent in the modern financial ambiance of public severity, characterized by a cry off in financial support for both state-run Tourism institutes and local TMs. This situation has hard-pressed various TMs, every so often bit by bit, to turn to online social platform as a moderately economical promotional tool with a universal reach. In spite of this drift, study on the use of facebook as destination branding paraphernalia remains inadequate (see, Kim and Fesenmaier, 2017; M. M. Mariani, Di Felice et al., 2016; Munar and Jacobsen, 2014; Szopiński and Staniewski, 2016; Szymczak, Kücükbalaban et al., 2016) view tourist criticisms in the social media as a most important dare for tourism corporations. Executives should trace the criticism forums and strive to lever them resourcefully. Administrators can also present patrons complaining venues such as Facebook which makes responding to complaints much easier. Facebook marketing is subset of Word-of-Mouth marketing. Customers have the facility to network with other patrons via company's Facebook-site. Word-of-mouth is extremely vital particularly in hospitality and tourism as products are hard to weigh up earlier to their using up because of their intangible nature (see, Ángeles Oviedo-García, Muñoz-Expósito et al., 2014).

\subsection{Research Gap}

Sabate, Berbegal-Mirabent et al., (2014) has done meta-analysis study of 412 scholastic papers where their conclusion depicts that a key quantity of the research papers considered the descriptive study of social media users mainly focuses on the subjective facet of online social platform with not as much of on the exploit of online public media by the social organizations. To fill up this shortfall, this article intends at creating a comprehensive thoughtful of "make uses of facebook" in touristry perspective that is deliberated as one of the leading businesses in the globe. The ground of analysis is travel marketers (TMs) that handle the attractions in a state level independently.

To realize the groundwork goal, this learning foremost notably reviews the articles of online social platforms in a touristry framework. After that, within the methodology section, the plan of the research is convoluted based on data mining and questionnaires analysis. The 
subsequent section is devoted to discuss findings and the results. Lastly, the end part argues the suggestion for TMs whilst spotting the confines of the research and signifying advance examine on the subject matter.

\subsection{Research Purpose}

The research of this article will be based on the current position of Nepalese along with the strengths and possible weaknesses of their website and social media presence. Ultimately, recommendations are drawn for Nepal in terms of possible technologies and applications that can be implemented. These will be broad and focus on different strategic aspects. This article aims to inspect online destination branding through social media TMs fan group.

\section{Methodology}

First of all, a data-mining procedure be used with an idea of discovering the official existence of travel managers (TMs) in online social platform like facebook and then, content scrutiny of TMs facebook fan pages be utilized. The analysis was made of Nepal's TMs with facebook page account on the root of elements of distinctiveness, approach towards consumer involvement and contribution, adoption, ease of use and newfangledness. The research for this study has been based on a benchmark analysis and online survey questionnaires too. The following destinations are the benchmark sample: (1) Nepal (2) Twelve earthquake affected tourism city destinations: Kathmandu, Lalitpur, Bhaktapur, Kavre, Sindhupalchowk, Dolkha, Rasuwa, Dhading, Tanahun, Pokhara, Chitwan, Lumbini. Below in figure 2 is a pictorial illustration of earthquake affected tourism destinations. 


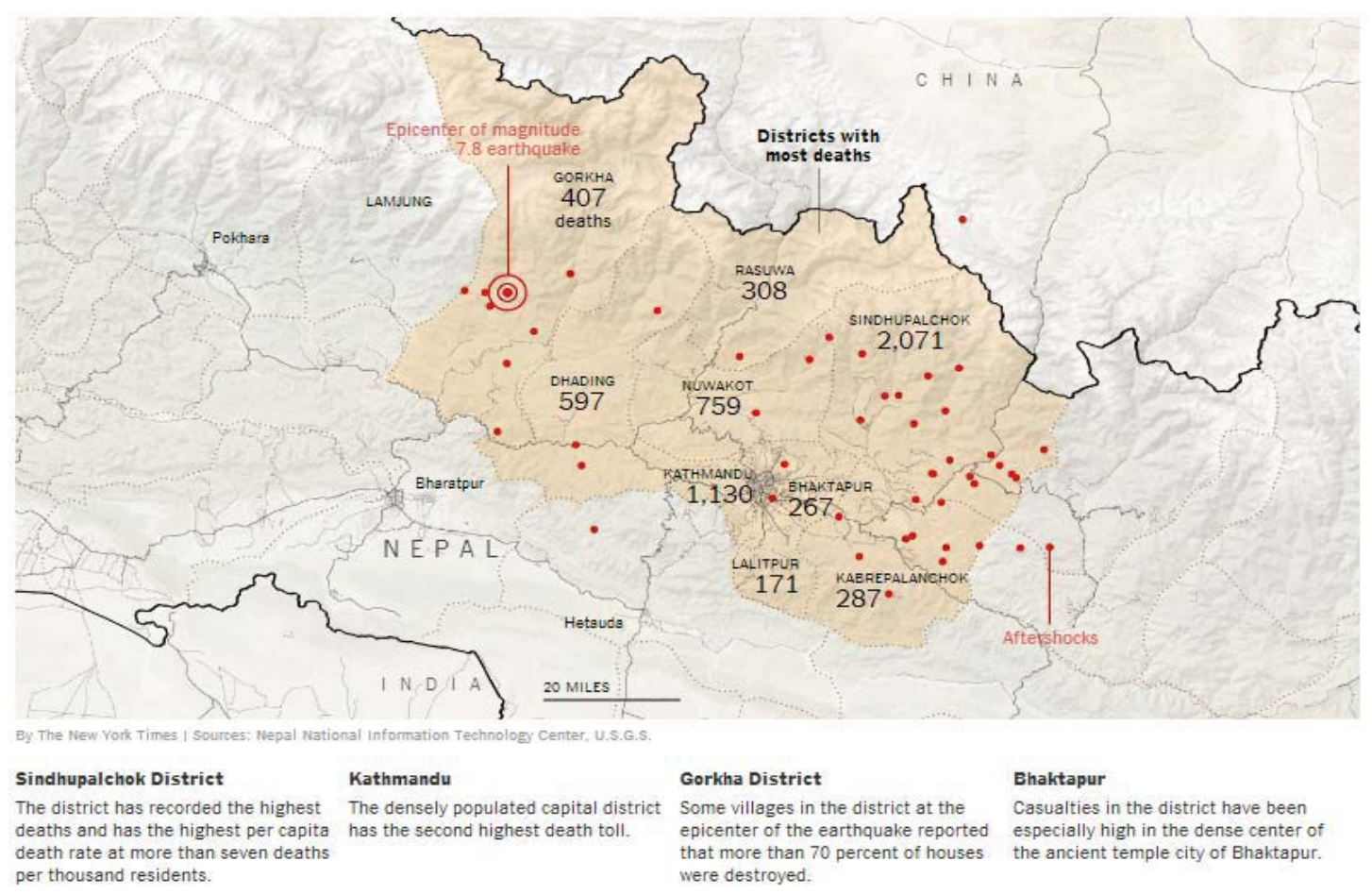

Figure 2 Pictorial demonstrations of twelve earthquake affected destinations in 2015 NEPAL.

Semi-structured interviews were carried out with a directory of open-ended questionnaire in five regions of Nepal with social medial TMs.

The inside story on or after those survey interviews yield a fuller understanding of how Nepalese regional/district TMs put into practice and position their online marketing strategies. The pollsters carrying out the interviews posed open-ended questions and took remarks of the reactions.

\subsection{Specific Analysis of Research Questions}

The opening stride in this research will be the investigative part to study the current state of practice of use of online social platform in insinuations for travel makers. For this we have following research questions.

1. Which styles of social media applications are adopted by travel makers (TMs) of Nepal?

How travel makers are exercising Facebook platform? What are the potentials of virtual tours to engage specific target customer on facebook as done by many other countries? 
Analysis:-This initial dimension is to spot websites of travel makers as a foundation for recognizing their online social web-links being there based on the hyperlinks provided in the websites of travel makers. Adopting data mining technique, a set of buzzwords will be signified to canvass to a search engine. The defined buzzwords might be like, tourism office, travel makers, official tourism association, general tourism club, Travel providers and national tourism board. The side pace will be to resolve the echelon of social media usage by travel makers. Therefore, websites will be very much inspected to hit upon the relations to social media networks in which TMs are present.

The second phase of this research is the online social platform as a means of destination branding (e-destination). For this we have following study question.

2. How destinations branding travel makers of Nepal are utilizing social media prior to the voyage to amaze today's hard-to-impress customers in context to Nepal?

Analysis:- Receiving opinion data from some travel makers, tourism providers, destination marketers and national tourism organizations(NTO) websites of Nepal-where by conducting pools and place investigate analysis on their social networks concerning news stories about their places of interests, interest in the tourist attractions, up to date events and campaigns, future events and fresh promotional programs.

The third ingredient of this study is the promising status/moment of perform to bring into play of "social media for social welfare" through travel \& tourism perfection. The adopted two ways are: endorsement of voluntourism and Promotion of contributions. We have following research questions for this.

3. What is the likelihood of promoting contributions via social media through travelling the destined areas which are affected by some kinds of natural disasters and needs some helping hands financially? Which online social platform in Nepal has a proclivity to smooth the progress of socially provoked chat on volunteer tourism and chances of helping hands through travelling the affected destinations? 


\subsection{Hypothesis Formulation}

Based on the interpretations, relating to the associations connecting individual variables and involvement, we can put together the following study hypotheses concerning the opening stride of our research:

H1. Travels makers (TMs) visual type of posts on facebook have greater impact on participation

H2. Travels makers (TMs) high frequency of posts brings the lower level of participation

H3. Travels makers (TMs) higher average length of the posts brings the higher level of participation

H4. Posts in late afternoon by Travels maker (TMs) have a encouraging impact on participation

H5. Posts in weekend by Travels maker (TMs) have an encouraging impact on participation

Multivariate ordinary least squares (OLS) regressions validate these hypotheses. OLS regression is a universal linear modeling practice that can be applied to model a single response variable on a quantity of dissimilar independent variables. OLS regression establishes to be mainly practical when variables display multivariate normality.

\section{Data Gathering and Methods}

Data set was composed from the official travel makers (TMs) Facebook pages at regional level of Nepal. Related share, comments and likes present on TMs facebook pages were extracted for this investigative research during the year 2015 (from the 1st of January to the 31st of December 2015), obtaining a total of 30,197 posts. Hays et al. (2013) model was selected for the analysis of the obtained posted contents like below. 
Table 1 Range of procedures designed for the study of contents.

\begin{tabular}{|l|}
\hline Users texts taxonomy (Status/moment, links, video, snapshots, others) (purposely formulated for this research) \\
\hline Quantity of 'likes' pro posts posted by users clients (Likes_C2C) \\
\hline Quantity of 'shares' pro posts posted by users clients(Shares_C2C) \\
\hline Quantity of 'comments' pro posts posted by users clients (Comments_C2C) \\
\hline Overall follower start of Year; overall fans start of month (specifically developed for this study) \\
\hline Overall follower End of Year; overall follower last part of month (purposely formulated for this research) \\
\hline
\end{tabular}

"Other": audio content

The rolling measures of participation are a progress over the presented empirical methods that have required to measure user participation with online social platform in the touristry area (Hays, Page et al., 2013; Khan, Khan et al., 2016).

Generic participation, designed on a monthly basis as below:

$$
\frac{(\text { Likes }+ \text { Comments }+ \text { shares })}{\text { Total Posts } * \text { Total Fans }(\text { end of the months) }} * 100
$$

Even though there exists quite a few software packages on social-media analytics functionality, my co-authors and TMs of Nepal helps me implement a new software tool explicitly for this investigative research, resides on revolutionary technologies "extractor module based on the Graph API technology" for organizing data recovered from the publicly available facebook social media .

User participation, measured on a monthly basis as formula:

$$
\frac{(\text { Likes C2C }+ \text { CommentsC2C }+ \text { sharesC2C) }}{\text { Posts }_{\text {users }} * \text { Total Fans }(\text { end of the months })} * 100
$$

NVivo software was used by authors to code data obtained from semi-structured interviews to independently classify vocabulary and patterns in the data. NVivo is software that supports qualitative and mixed methods research. Taking into consideration the existing literatures on tourism and hospitability, coding is done using an recursive advance of data correlation (Pike and Page, 2014). Further the enhancement of analysis is made possible by mingling the data 
obtained from interview with the quantitative results (Kudeshia, Sikdar et al., 2016). On the whole, a magnitude of argument materialized from this progress (like, intrinsic relations of TMs with facebook followers, issues and idea of social movement, viewers expansion, tackle to levy the efficacy of facebook exploit) present a deeper perceptive of the outcome of the quantitative scrutiny.

Table 2 In general number of posts for Nepalese district TMs in 2015.

\begin{tabular}{|l|l|l|l|}
\hline Region & Total posts & Total posts TMs & $\begin{array}{l}\% \text { Posts TMs on Total } \\
\text { posts }\end{array}$ \\
\hline Kathmandu & 8467 & 2665 & $31.5 \%$ \\
\hline Latitpur & 3341 & 2320 & $69.4 \%$ \\
\hline Bhaktapur & 2993 & 1469 & $49.1 \%$ \\
\hline kavre & 2644 & 1330 & $50.3 \%$ \\
\hline Sindhupalchowk & 2889 & 815 & $17.9 \%$ \\
\hline Dolkha & 2077 & 535 & $25.7 \%$ \\
\hline Rasuwa & 1649 & 963 & $58.5 \%$ \\
\hline Dhading & 1615 & 1109 & $68.6 \%$ \\
\hline Tanahun & 1524 & 968 & $63.5 \%$ \\
\hline Pokhara & 1484 & 1449 & $97.6 \%$ \\
\hline Chitwan & 1399 & 1040 & $74.3 \%$ \\
\hline Lumbini & 1153 & 833 & $79.2 \%$ \\
\hline Overall Total & 31,235 & 15,496 & \\
\hline
\end{tabular}

\section{Interpretation of Results}

Throughout 2015, travel marketer (TMs) facebook pages witnessed an overall of 31,235 posts, of which 15,496 (49.6\%) were posts made by the TMs themselves as illustrated in Table 2 which hints that the aim of shared connection among TMs managers and followers has been realized, specified that $50 \%$ the posts posted from followers. The unequivocal big-hitter in terms of overall posts was the Kathmandu TMs facebook page, chased by Lalitpur, likewise Bhaktapur as well had a exceedingly soaring gain of posts by followers, as did chitwan and Lumbini. In general, it is figured out that the pinnacle five district TMs in conditions of overall Facebook posts are kathmandu, Lalitpur, Bhaktapur, Kavre and Sindhupalchowk 
which are focused in pale yellow and intense red dots in northern and central Nepal and can be seen in figure 3. Now excluding that of users and by focusing the posting activity of the TMs themselves, the broad-spectrum outcome do not alter greatly, apart from that the influential at this time are Kathmandu, Lalitpur, Bhaktapur, pokhara, and Chitwan as can be seen in figure 4. The districts with the utmost portion of posts by followers are instead Pokhara, Kathmandu, Lumbini, and Llitpur. keeping to one side Tanahun district (low down overall posts), kathmandu, Lalitpur, and Pokhara are the districts whose followers post in a good number enthusiastically. Almost all posts posted by TMs in 2015 consist of snapshots of approximately ( $\geq 82 \%)$, chased by web-links $(\geq 11 \%)$ and short clips $(\geq 6 \%)$. The theme-type itemization for each district TMs facebook is demonstrated in figure 4.

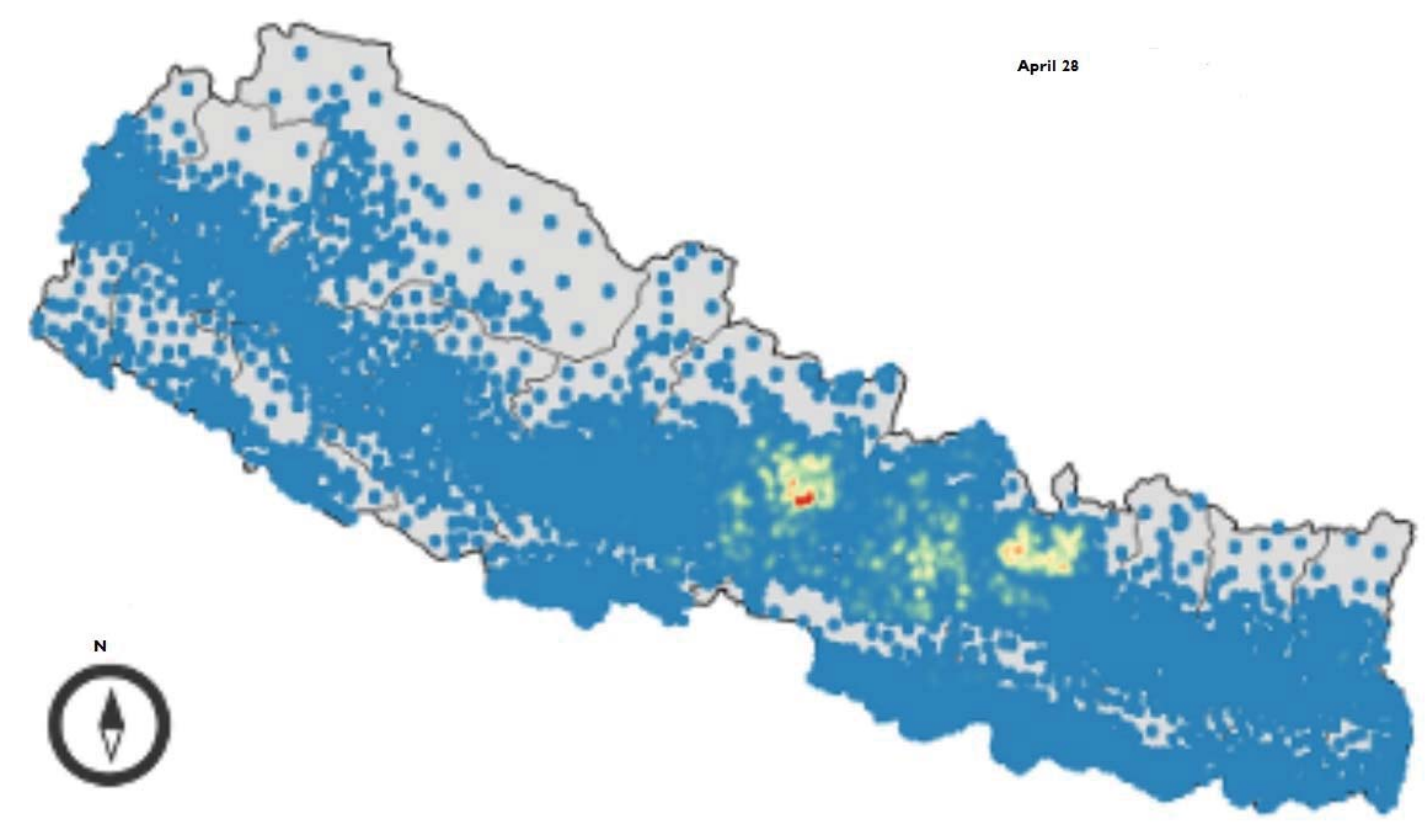

Figure 3 Severity depict of the posting undertaking on the Nepalese district TMs' facebook page in 2015.

Source: Nepal Tourism Board 


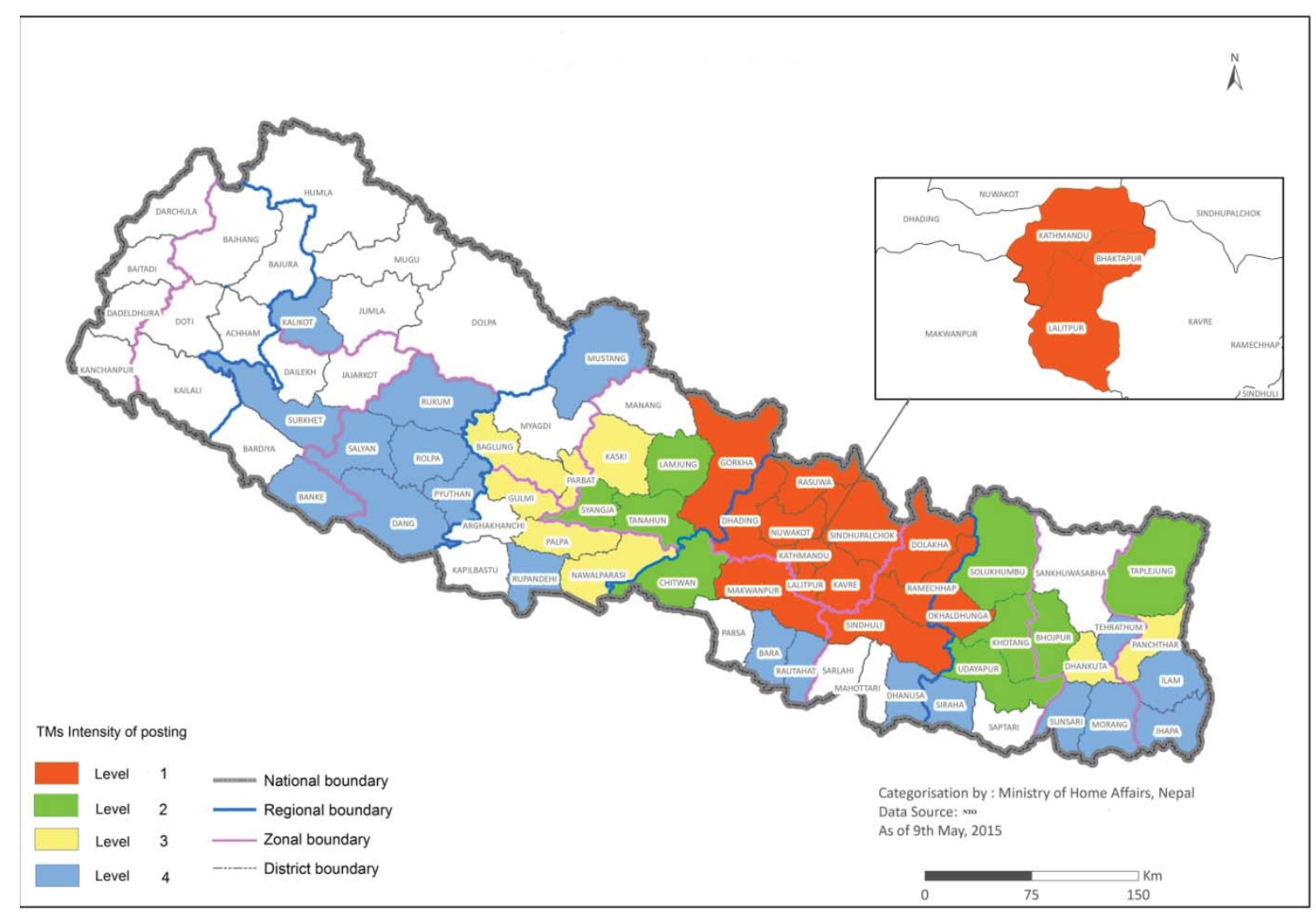

Figure 4 Severity depict of the posting undertaking conveyed by the Nepalese district TMs in 2015.

Source: Nepal Tourism Board

By and large, major five district TMs in requisites of fan activity are also the peak five district TMs in the state of affairs of postings. As a result, it emerges that soaring posting action on TMs facebook page overlaps with soaring fan comments likes and shares. Apart from hardly any excuses, most of the user activities are instigated on or after fans and followers i.e., the TMs enter into publishing and propagandizing doings even so is hardly ever concerned in commenting/sharing/ liking activities). 


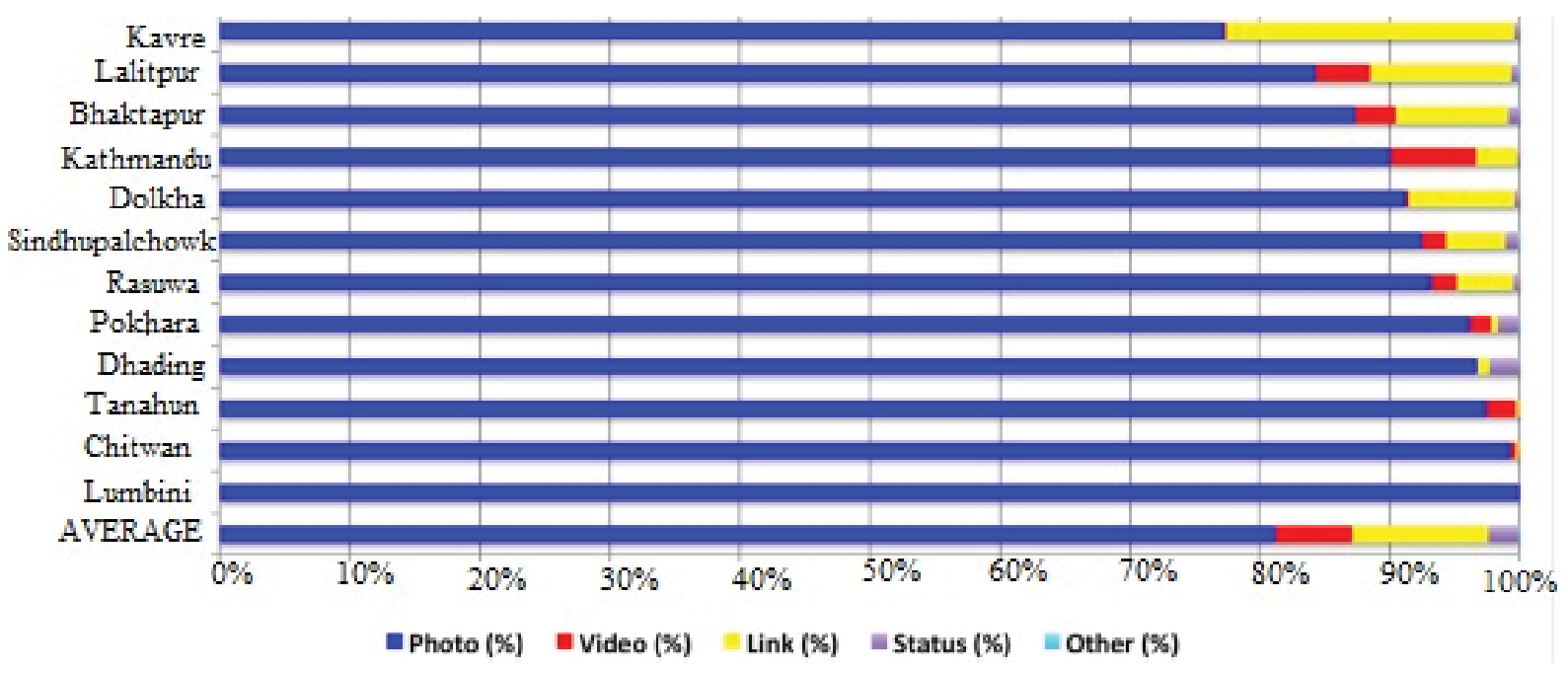

Figure 5 Varieties of posts by the Nepalese district TMs (theme-type itemization for each district TMs facebook).

Lumbini, Chitwan, Tanahun, Dhading, and pokhara districts are fond of circulating snapshots, and passionately repost most on the whole. The cases of kavre as well as dolkha give the impression to catch the eye on the whole depiction, typically due to their commonly use of web-links for emphasizing current and upcoming events. Curving now to spotlight on fans and followers activities in selected twelve districts TMs facebook pages can be noted in figure 5, kathmandu, pokhara, lalitpur, and Bhaktapur are the principal TMs in requisites of likes (with 703,032; 617,443; 310,262; 270,444; and 243,998 Likes correspondingly), Figure 6 visually points up the state of affairs across district TMs. The districts with utmost figure of users at the end of the year 2015 shown in table 3 are by and large same as to those with the uppermost figures of Shares, Comments and Likes with the exemption of lumbini, pokhara, Tabhun and kavre where, in spite of moderate actions and activities conducted by users, had a sturdy grow in its following fans as can be seen in table 3.

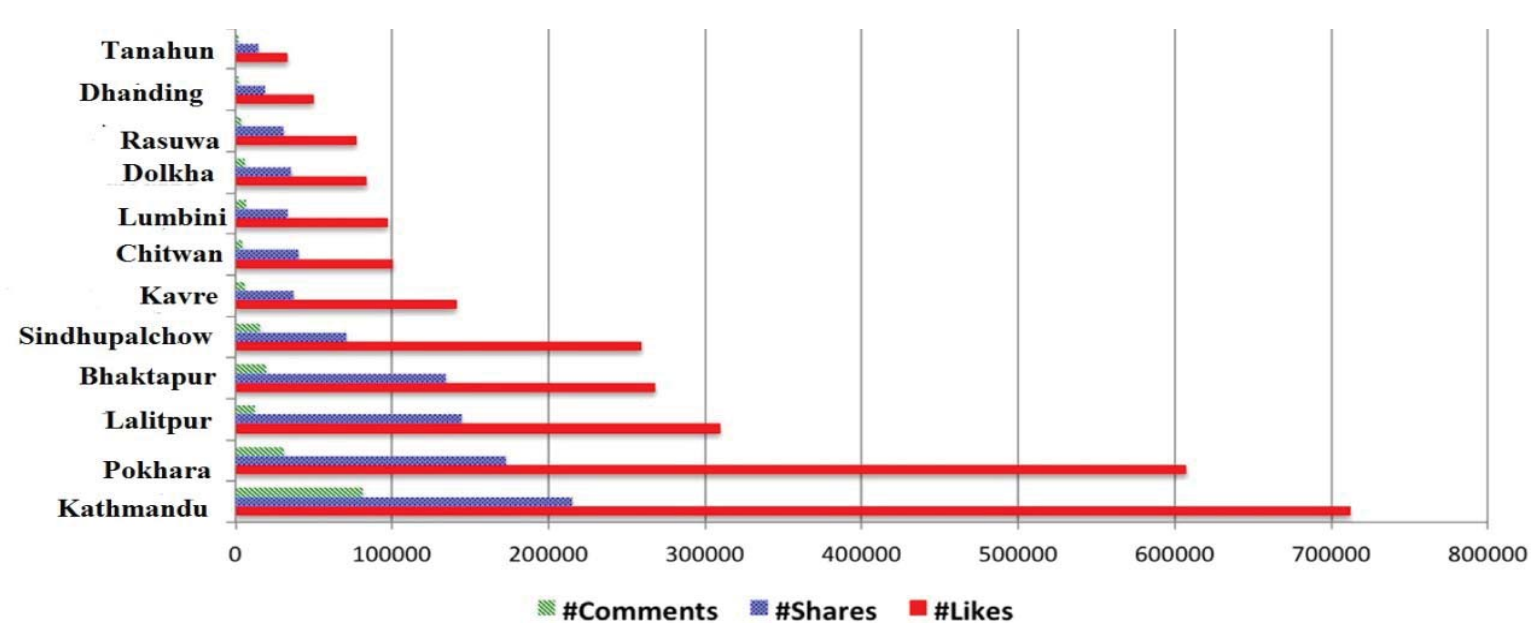

Figure 6 Facts of users activities by the Nepalese district TMs and their comments, shares and likes in 2015. 
Nonetheless, as is obvious from Table 3, the leading proportion raises during 2015 took place for TMs of minor districts like Dolkha (+8146.7\%), Lumbini (+493.4\%) also Tanhun $(+188.1 \%)$ as their facebook pages were most recently created and opened for public and fans. Because of this in table 3, during the start of the year 2015, the fans following/users number shows very thin.

Table 3 In general statistics of facebook users and yearly alteration in 2015.

\begin{tabular}{llll}
\hline Districts & \#Users & \#Users & Change (\%) \\
& (beginning of the year) & (closing of the year) & \\
\hline Kathmandu & 135,112 & 228,888 & 69.4 \\
Lalitpur & 154,256 & 225,522 & 46.1 \\
Bhaktapur & 66,687 & 77,172 & 15.7 \\
Pokhara & 66,123 & 89,246 & 34.9 \\
Chitwan & 54,998 & 79,189 & 43.9 \\
Lumbini & 11,306 & 67,121 & 493.4 \\
Kavre & 13,759 & 34,260 & 149.0 \\
Sindhupalchowk & 13,234 & 29,132 & 120.1 \\
Dhading & 17,338 & 29,668 & 71.1 \\
Rasuwa & 19,976 & 22,821 & 14.1 \\
Tanhun* & 4,566 & 13,156 & $8146.7^{*}$ \\
Dolakha* & 109 & 8,989 & \\
\hline
\end{tabular}

* Smallest region

\subsection{Determinants of Participation}

This part center on the features controlling district-TMs-facebook-pages followers' activities and their participation and analyze them separately. More exclusively, the general populations of postings initiated by Nepalese district TMs during 2015 their analysis and their relationship with different variables: i) post type; ii) posts distribution; iii) TMs postings time span; iv) frequency of posting. As noted earlier, most of the Nepalese regional TMs are apt to post mostly snapshots. Analysis shows that snapshots and videos are also the type of content that elicits most comments in figure 7. 


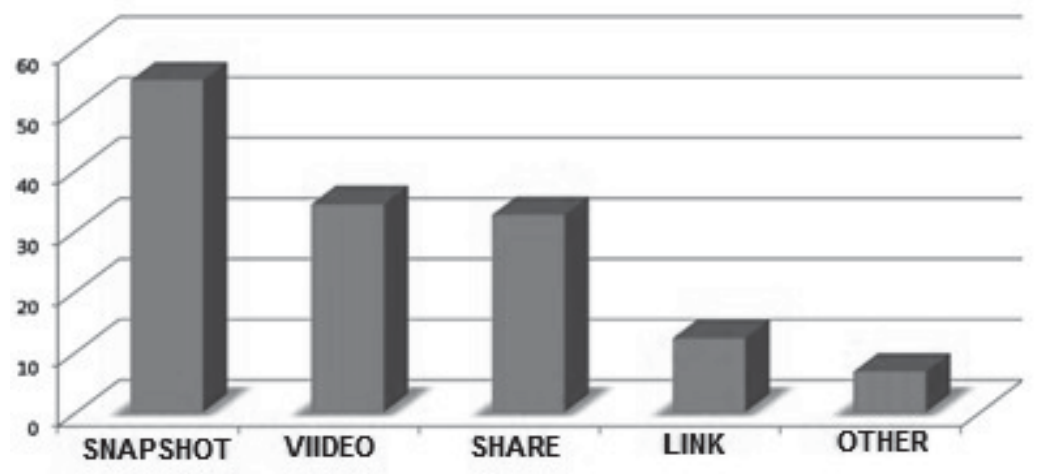

Figure 7 Standard generic participation for fans' actions based on posts types in 2015.

While reviewing the whole population of posts, it is observed that in almost $30 \%$ of cases, the post is of 200 characters in average while bulk of them lies between 100 to 400 characters. So far TMs posting time span is concerned, it is observed that $30 \%$ cases from postings with 200 characters generates peak of participation which shows that time-span of posts have an alarm on participation. The scrutiny on the by and large number of published posts reveals one facts that huge proportion of TMs post are morning posts or either late afternoon posts during normal working days of a week, even if quite a lot of also post overnight. Content made in the evening gives the impression of encouraging result on inclusive/generic participation, possibly for the reason that such advertised posts are fewer in quantity and for that reason easily spotted, besides because fans and followers by a large amount access facebook in the late afternoon simply (see figure 7 below).
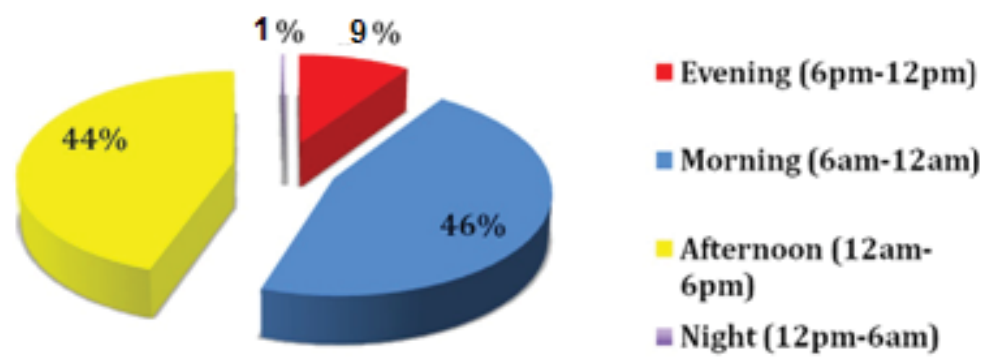

Figure 8 Allocations of promotes and announcing as per the TMs facebook publishing hour in 2015.

The study demonstrates that the greater part of TMs posts are posted throughout Monday to Friday, only $\geq 15 \%$ of TMs posted material are at some point in the weekend. It is not easy to spot a definite association between content made at weeks' days with the ensuing participation. Which means story and content made over the weekend draws out lofty participation. It comes into view that TMs posting actions and the reactions at posted contents by fans and followers are uneven: TMs promotes their posts mostly during Monday to Friday 
whereas fans mingle actively to those posts throughout the weekend.

The consequence of posting rate on participation is illustrated in figure 9, which give an idea that highest participation depends on low rate of posting. In a nutshell the lesser the rate of publishing posts, participation rates elevates. In other ways it reflects that huge facebook fans and followers means huge number of posts which shows unproductive results, and do not grasp elevated participation.

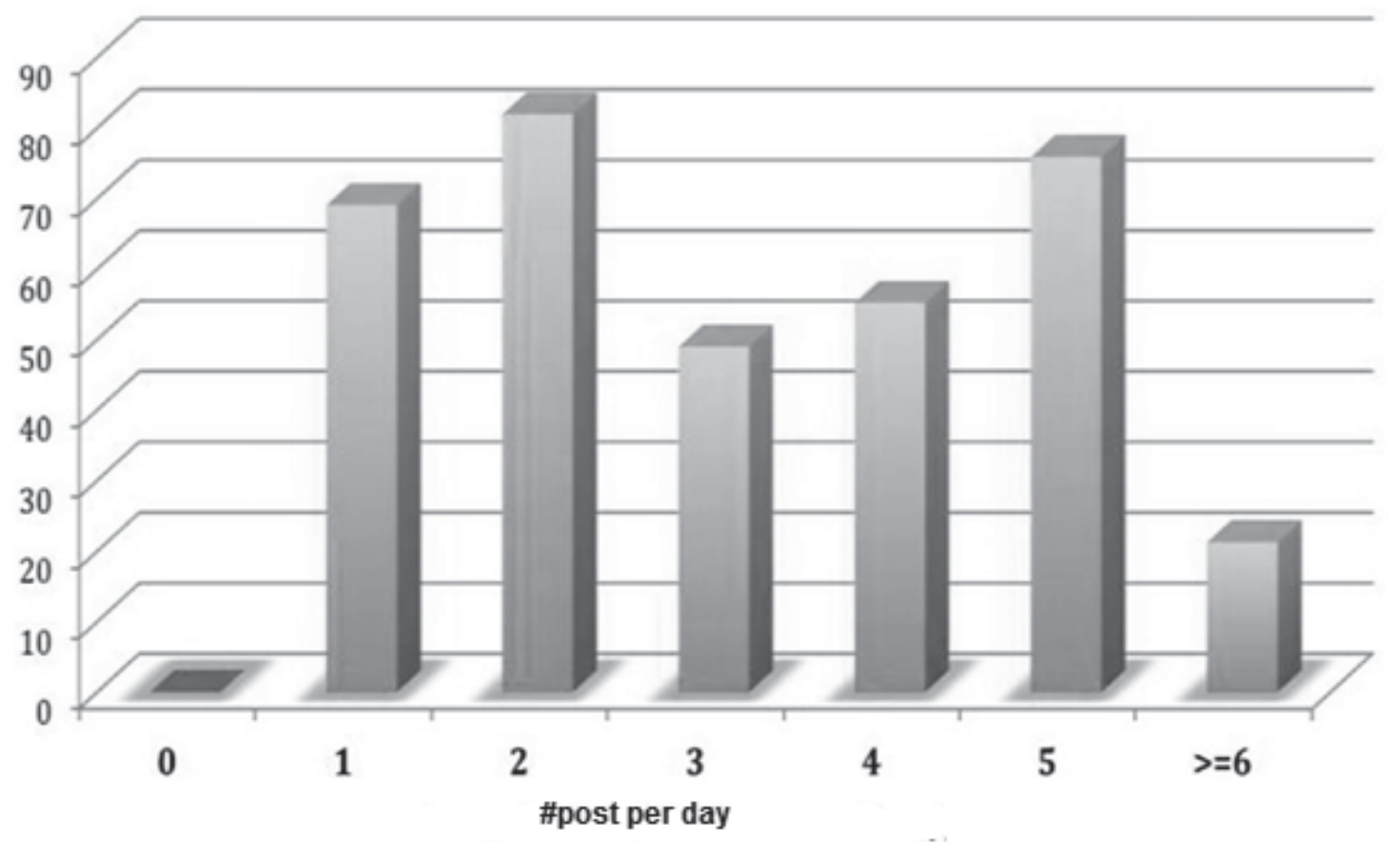

Figure 9 Average generic participation per fans' reactions on TMs' post (2015 each day data)

\subsection{Empirical Analysis}

The observed scrutiny explains that in country like Nepal, in month of January, social participation on social media sites of TMs facebook page posts is huge, but then afterwards goes on falling down slickly until May. Still, there gives the impression of not to be any straightforward correlation connecting posting months and the participation patterns. Table 4 lists the variables on hand, which also corroborate the correlation between these variables and participation. Section 3.2 above is our hypothesis formulation. Following are the variables integrated in the replica: Participation as the dependent variable regressed against Snapshot, Moment, Repeated posts, Normal post time-span, Late afternoon_posts, Early_posts, Endweek posts are used as independent variables. Furthermore, as two control variables, geography and months of posts are integrated. First of all every one month was incorporated as legitimate variable as such a dummy was produced counting only those months recognized as having the relative peaks of participation and Geography center is another coded dummy. Table 5 shows the results of the regression analysis. 


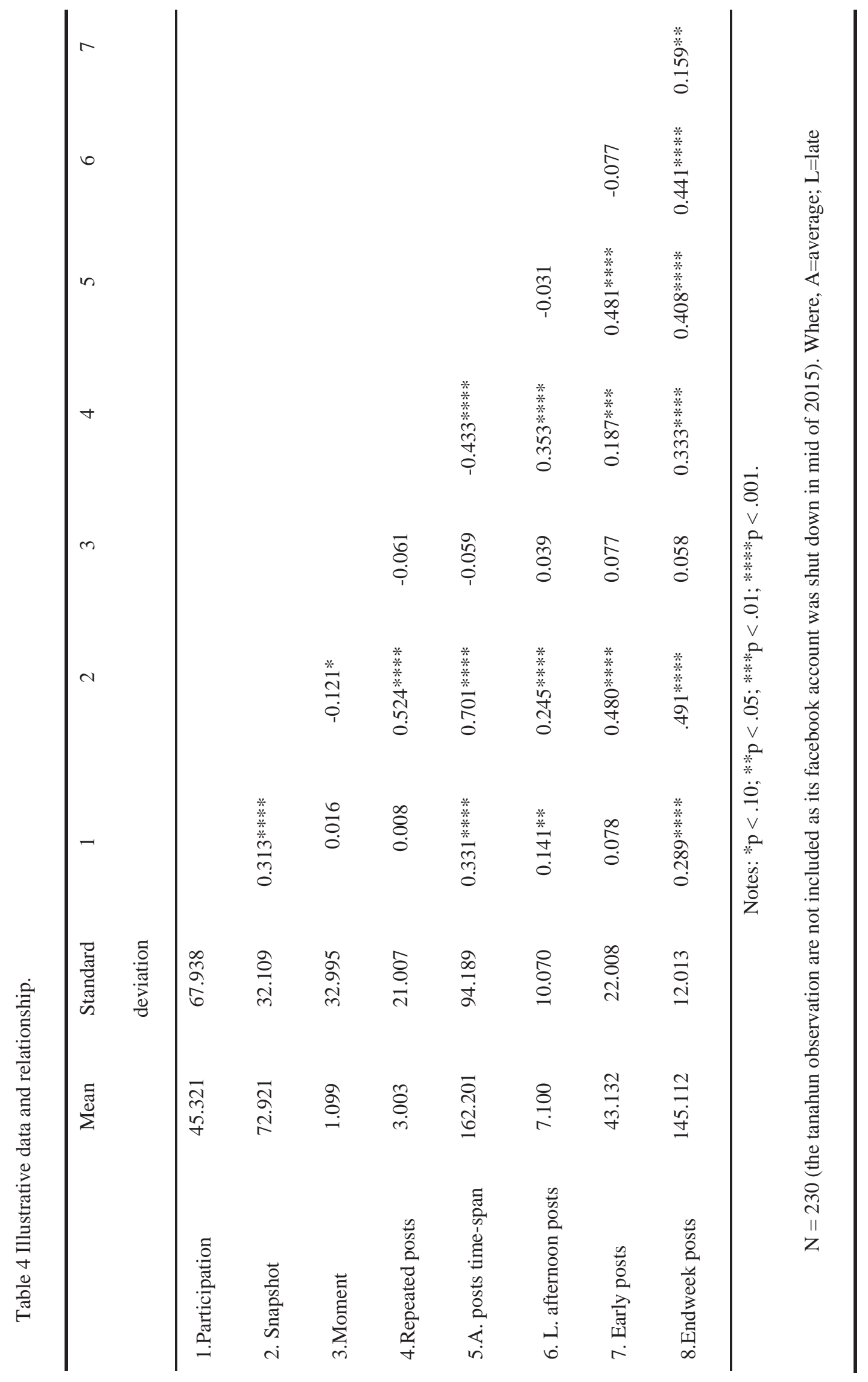




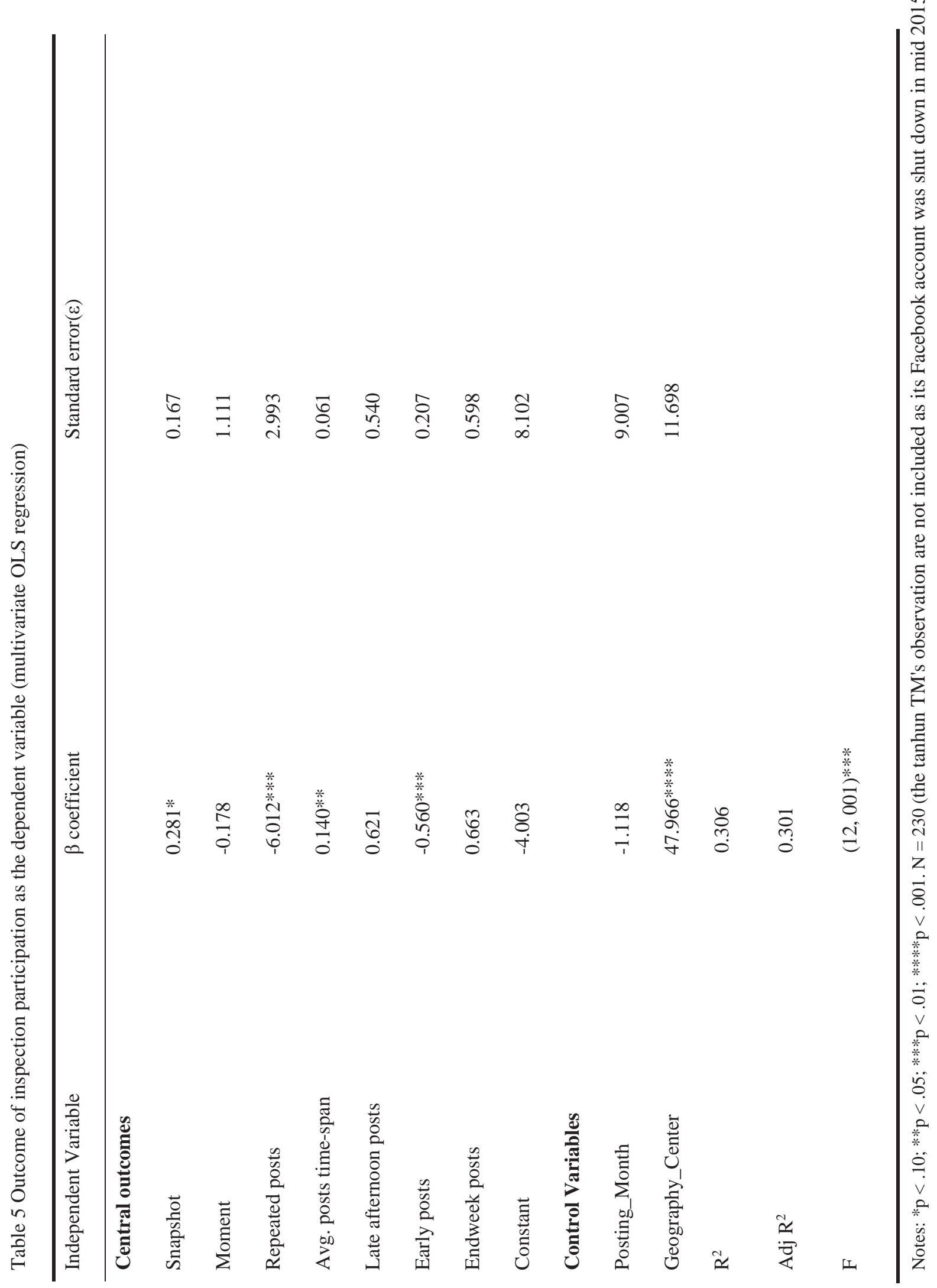


The projected replica comprises a good fit, decoding $\geq 33 \%$ of the variation. In view of the anticipated assumptions: with nearly $11 \%$ statistical impact, hypothesis (H1) not been able to abandoned; Hypothesis (H2) and hypothesis (H3) as well not been able to abandoned with $\geq 1 \%$ numerical importance; while hypothesis (H4) and hypothesis (H5) kick off outcomes which are not numerically noteworthy. In consequence, the retro gradation consequences put forward that Nepalese regional TMs boost their participation by slowing down their rate of posting, and by first-rating mainly image content like snapshots. Reposting all through the end of week optimistically influences participation whose amount is insignificant statistically. In opposite, entry of posts in the early hour of days have a hefty unenthusiastic shock on participation perhaps merely for the reason that TMs are nearly all active all through the morning, whereas MTs facebook followers and users seems as if least lively at that moment in time. Actually the fat associations among picture substance on MTs facebook pages with participation back up the fact that prospective voyagers who make use of facebook social platform are fascinated with imagery of the places of interest as well as tourist sites already visited by them or future preparation to holiday. The fact is coherent as a result of well-built correlation between going to places of interest and perception-making medium interrelated to visiting the attractions usually featured in tourism studies (Jeon, Ahn et al., 2016), and the veracity that TMs tell the different tourists' liking for visual content sharing (Kudeshia, Kudeshia et al., 2017). So far post size is concerned, the affirmative bond among reasonably lengthy attachments and participation is clarified by that information which travelers give the impression to have an inclination for new facts-loaded, storyline contented along with that TMs are apt to create just that sort of content for the reason to notify in a informal style. The unenthusiastic significance of the rate of posting on participation is possibly attributable to fan's time restraints. Recurrent texting entails giving out larger total of posts throughout a specified time span. Yet, web enthusiast may not have sufficient occasion in a given time-span to slot in through every part of the posts posted during that time interval. Moreover, in view of the fact that users have a partiality to gaze newest posts on a facebook, older posts dislodged by the fresh ones, thus entertain smaller quantity of feedback reactions from fans, in so doing ensuing inferior participation. Early made contents on facebook involves downbeat blow on participation since TMs facebook fans appear to deface their time in the late afternoon and at end of the day. As fans retort largely to new relevant content, which support posts placed in the late afternoon. Here the outcomes contour in the midst of data concerning the practice of the social media facebook dais, illustrates so as to majority fans and followers approach in facebook in morning or afternoon (Karjaluoto, Karjaluoto et al., 2016). The control variable "geography" has an optimistic significance on participation, through a top scale for the valley and Centre, where several of the most active TMs (Tafesse and Tafesse, 2016) are located. In conclusion, the month of posting looks as if to have no manipulation on participation. 


\subsection{Social Networking Approach}

Interviews done with pertinent key witnessers at 12 district level TMs discovered that, to a few degree, Nepalese regional TMs exercise social media merely to publicize and prop up in a conventional way. Nevertheless some TMs (such as chitwan and Lumbini) deem that social platform TMs should be used as a feature of social narration, rather than as simply a further conduit for advertising. Travel marketers of small districts of Nepal has adopted facebook marketing of tourists sites in a more experimental approach after 2015 Nepal earthquake in order to chat in their own way and with distinguished content. Among such group, they cope to influence educational content in a further artistic and enlighten way. Analysis of posts after 2015 earthquake highlights the fact that the posted contents that breed $\leq 80$ comments were $\geq 160$ in all, dispersed as follows: 87 (61.1\%) for Kathmandu, 27 (19.2\%) for Bhaktapur, 18 (13.3\%) for Lalitpur, 7 (4.9\%) for pokhara, 4 (2.8\%) for chitwan and 1 (0.8\%) for both Lumbini and Sindhupalchowk. The highest scorer of comments was posts with snapshots accounting 151(98\%), subsequently moment's posts accounting 9(2\%). An added modus operandi often adopted by quite a few Nepalese TMs is quizzes. Investigative study of posted content verifies imagery posts holds absolute influence in favor of branding a tourist sites via facebook marketing, the capability to attract greater feedbacks in terms of share, likes and comments drastically improved, and in this manner boost up user participation. Severely affected earthquake regions like Sindhupalchok, Kavre, and Kathmandu are undoubtedly those tourists' sites that have valued these facts delightfully for their destination branding and attracting voluntourism.

\subsection{Significant Contribution}

Most of previous studies explain the fact that participation upshots can very much depends on in what way the participation basis are formulated. In our findings if we set up metrics standardized by users number on monthly rolling basis, the best entertainers are: Kathmandu, Lalitpur, and Pokhara see Figure 5 monthly basis; and based on rolling base, they are Kathmandu, Lalitpur, and Bhaktapur. Conversely, by using basis not standardized by the users' quantity instead rate of picture changes then Chitwan, Lumbini, and Kavre are the finest entertainer. This peculiarity is a considerable input of this article that assist to highlight in what way participation basis can promisingly be ambiguous, when it is blurred in what way those foundations are formed. While the prose on facebook return on investment (ROI) is swiftly mounting (Rahman, Suberamanian et al., 2016), the consequences of the quantitative content study, pooled with interview data as qualitative data with districts travel managers advocate that there is no common accord on a particular principal basis for testing triumph in social media strategies. More expressly, the meeting with TMs tinted that there does not exist precise set of metrics set out all the time across tourism organizations to evaluate the 
accomplishment of social networking. Certainly, scores of respondents assumed that their district travel managers are not predominantly paying attention merely in quantity of "Likes" pressed on their official facebook pages. The TMs, in measuring the hit of its social media promotion in attracting voluntourism in Nepal, must also seize into relation the intensity of participation. It is extra essential to perceive in what way fans "respond" to a TMs facebook content in provisos of emotion, more willingly than just endowing "frigid numbers" to review the usefulness of different strategies of social networking. Besides, not any of the talked travel marketers' managers with facebook page are rating saleable upshots that are; how much their policy on social networking are growing the size of tourism services packages. Response to this argument is pointless, given that the greater part of TMs facebook sites are created principally for advertisement and publicity, and by far no vend tourism products and services.

\section{Conclusions}

Kindle of this study visibly demonstrated that all Nepalese district TMs has its own idiosyncratic behavior of exercising along with explaining strategies of social networking on facebook. Travel marketers of valley and north-central Nepal falls under top five TMs lists so far number of facebook posts is concerned. Nonetheless, inspecting further cautiously at the participation data with the management does in place, an added well-granule difference comes into sight, between regional TMs that exploit/infer facebook in a lively and new fashioned ways vs. those that exercise/understand facebook marketing in a much inactive way.

Firstly, our conclusion signify that visual content like snapshots and more or less extended posts have a methodically-meaningful upbeat weight on TMs ' facebook participation metrics, despite the fact that greater number of posting rate and early posting per day have a unenthusiastic blow on participation. The well-set linkage flanked by photo substance and participation may be credited to the entrenched link among going to places of interest and perception creating medium(Pongpaew, Speece et al., 2017), and the popularity of imagery in TMs posts also confirms that TMs identify tourists' inclination for visual content sharing (Farivar, Farivar et al., 2017). The truth that reasonably lengthy posts boost participation may be credited to the piece of information that TMs are apt to turn out information-rich, sequence of events themes in an informal simulated technique for the reason that they are setting out to put in the picture travelers and sightseers. Soaring contents rate of recurrence has a downbeat blow on participation primarily for the reason that, given time restriction, size of posts matters as facebook fans can engage with on any particular time span. Moreover, facebook fans have a tendency to reflect on only the hottest content, previously missed posts will not entertain the same amount of feedbacks. Early posts have an unenthusiastic carry on participation as data on the handling of the facebook platform show (Ge and Gretzel, 2017). Facebook users have a 
tendency to check subscribed pages in the late afternoon as well as at nighttime, thus fans will respond to the most recent contents posted in the late afternoon. As a result of tallying the methodological examination and talks completed during this research, a number of decision-making connotations for Nepalese regional TMs can be produced.

Secondly our conclusion undoubtedly signifies that TMs of any other geographical contexts of country level or district level or local level should deliberately arrange image postings to bring forth their fans' participation. Taking into consideration of vacationers' known inclination for image postings (Busalim, 2016), this loom is apt to lift shared commotion on TMs facebook pages. Furthermore, inserting such photos and clips in judgment survey during events and calamities vivifies the repute of their tourist sites by generating encouraging word-of-mouth branding (Getz and Page, 2016; Hristov and Zehrer, 2015; Pearce, 2015; Same and Solarte-Vasquez, 2014; Wozniak, Stangl et al., 2016).

Skillfulness of TMs employees is in general play major role in making popular of facebbok pages by keeping up to date with the hottest improvements in tourist sites branding. Taken as a whole, relating facebook with new promotion stuffs possibly will tile the technique for Nepalese districts TMs facebook destination branding challenge in upcoming days. Believing this, authors suppose that district level Nepalese TMs restrains a lot opportunity for upgrading as well as believed to level themselves aligned with other akin TMs in new parts of the world.

This research clings to a quantity of limitations. Foremost the study was conducted in a circumstantial geological milieu (Nepal) in earth quake affected regions, where tourism sponsorship is directed mainly by the central government. As a result, this research cannot be inferred to nations where public private partnership, plays a leading responsibility in touristry branding. These conclusions could be further summarized by inflating the model to incorporate provincial and state TMs in other nations. Besides, our conclusion might be attention-grabbing to level against other tourist places in Asia. Subsequent, border line of this study is facebook content specific plus just one recent year (2015) TMs strategies data. In forthcoming effort the moment outline of the study could be extended to incorporate historical past year's record data, or simplified with new up to date data.

\section{Reference}

Ángeles Oviedo-García, M., Muñoz-Expósito, M., Castellanos-Verdugo, M., \& Sancho-Mejías, M., (2014) "Metric proposal for customer engagement in Facebook," Journal of Research in Interactive Marketing, vol. 8, no. 4, pp. 327-344.

Aspasia, V., \& Ourania, N., (2014) "Social media adoption and managers' perceptions," 
International Journal of Strategic Innovative Marketing, vol. 1, no. 2, pp. 61-73.

Ballings, M., \& Van den Poel, D., (2015) "CRM in social media: Predicting increases in Facebook usage frequency," European Journal of Operational Research, vol. 244, no. 1, pp. 248-260.

Bilgihan, A., Barreda, A., Okumus, F., \& Nusair, K., (2016) "Consumer perception of knowledge-sharing in travel-related Online Social Networks," Tourism Management, vol. 52, no., pp. 287-296.

Busalim, A. H., (2016) "Understanding social commerce: A systematic literature review and directions for further research," International Journal of Information Management, vol. 36, no. 6, pp. 1075-1088.

Dijkmans, C., Kerkhof, P., \& Beukeboom, C. J., (2015) “A stage to engage: Social media use and corporate reputation," Tourism Management, vol. 47, no., pp. 58-67.

Farivar, S., Farivar, S., Turel, O., Turel, O., Yuan, Y., \& Yuan, Y., (2017) "A trust-risk perspective on social commerce use: an examination of the biasing role of habit," Internet Research, vol. 27, no. 3, pp. 586-607.

Ge, J., \& Gretzel, U., (2017) "The Role of Humour in Driving Customer Engagement," Information and Communication Technologies in Tourism 2017, pp. 461-474: Springer.

Getz, D., \& Page, S. J., (2016) "Progress and prospects for event tourism research," Tourism Management, vol. 52, no. 6, pp. 593-631.

Hays, S., Page, S. J., \& Buhalis, D., (2013) "Social media as a destination marketing tool: its use by national tourism organisations," Current issues in Tourism, vol. 16, no. 3, pp. 211-239.

Hristov, D., \& Zehrer, A., (2015) “The destination paradigm continuum revisited: DMOs 
serving as leadership networks,” Tourism Review, vol. 70, no. 2, pp. 116-131.

Jeon, H., Ahn, H. J., \& Yu, G. J., (2016) "What makes people react to the posts on the brand pages of mobile social network games?," Online Information Review, vol. 40, no. 3, pp. 435-448.

Jucan, M., Jucan, C., \& Rotariu, I., (2013) "The Social Destination": How Social Media Influences the Organisational Structure and Leadership of DMOs.” no. 78, pp. 1410.

Karjaluoto, H., Karjaluoto, H., Munnukka, J., Munnukka, J., Kiuru, K., \& Kiuru, K., (2016) "Brand love and positive word of mouth: the moderating effects of experience and price," Journal of Product \& Brand Management, vol. 25, no. 6, pp. 527-537.

Kavoura, A., (2014) "A conceptual communication model for nation branding in the Greek Framework. Implications for Strategic Advertising Policy," Procedia-Social and Behavioral Sciences, vol. 148, no. 1, pp. 32-39.

Kavoura, A., \& Stavrianea, A., (2014) "Economic and social aspects from social media's implementation as a strategic innovative marketing tool in the tourism industry," Procedia Economics and Finance, vol. 14, no. 5, pp. 303-312.

Ketter, E., (2016) "Destination image restoration on facebook: The case study of Nepal's Gurkha Earthquake," Journal of Hospitality and Tourism Management, vol. 28, no.1, pp. 66-72.

Khan, I., Khan, I., Dongping, H., Dongping, H., Wahab, A., \& Wahab, A., (2016) "Does culture matter in effectiveness of social media marketing strategy? An investigation of brand fan pages," Aslib Journal of Information Management, vol. 68, no. 6, pp. 694-715.

Kim, J., \& Fesenmaier, D. R., (2017) "Sharing tourism experiences: The posttrip experience," Journal of Travel Research, vol. 56, no. 1, pp. 28-40.

Kudeshia, C., Kudeshia, C., Kumar, A., \& Kumar, A., (2017) "Social eWOM: does it affect 
the brand attitude and purchase intention of brands?," Management Research Review, vol. 40, no. 3, pp. 310-330.

Kudeshia, C., Sikdar, P., \& Mittal, A., (2016) "Spreading love through fan page liking: A perspective on small scale entrepreneurs," Computers in Human Behavior, vol. 54, no.3, pp. 257-270.

Leung, X. Y., Xue, L., \& Bai, B., (2015) "Internet marketing research in hospitality and tourism: a review and journal preferences," International Journal of Contemporary Hospitality Management, vol. 27, no. 7, pp. 1556-1572.

Luo, Q., \& Zhong, D., (2015) "Using social network analysis to explain communication characteristics of travel-related electronic word-of-mouth on social networking sites," Tourism Management, vol. 46, no.3, pp. 274-282.

Mariani, M., Baggio, R., Buhalis, D., \& Longhi, C. (Eds.). (2014) Tourism Management, Marketing, and Development: Volume I: The Importance of Networks and ICTs (Vol. 1). Springer.

Mariani, M. M., Buhalis, D., Longhi, C., \& Vitouladiti, O., (2014) "Managing change in tourism destinations: Key issues and current trends," Journal of Destination Marketing \& Management, vol. 2, no. 4, pp. 269-272.

Mariani, M. M., Di Felice, M., \& Mura, M., (2016) "Facebook as a destination marketing tool: Evidence from Italian regional Destination Management Organizations," Tourism Management, vol. 54, no., pp. 321-343.

Munar, A. M., \& Jacobsen, J. K. S., (2014) "Motivations for sharing tourism experiences through social media," Tourism Management, vol. 43, no.3, pp. 46-54.

Pearce, D. G., (2015) "Destination management in New Zealand: Structures and functions," Journal of Destination Marketing \& Management, vol. 4, no. 1, pp. 1-12. 
Pike, S., \& Page, S. J., (2014) "Destination Marketing Organizations and destination marketing: A narrative analysis of the literature," Tourism Management, vol. 41, no.2, pp. 202-227.

Pongpaew, W., Speece, M., \& Tiangsoongnern, L., (2017) "Social presence and customer brand engagement on Facebook brand pages," Journal of Product \& Brand Management, vol. 26 , no. 3 , pp.

Popesku, J., \& Pavlović, D., (2013) "Competitiveness of Serbia as a tourist destination: Analysis of selected key indicators," Marketing, vol. 44, no. 3, pp. 199-210.

Rahman, Z., Suberamanian, K., Zanuddin, H., Moghavvemi, S., \& Nasir, M. H. N. M., (2016) "Social Media Engagement Metric Analysis-" Study on Fan Page Content"," Journal of Telecommunication, Electronic and Computer Engineering (JTEC), vol. 8, no. 8, pp. 71-76.

Sabate, F., Berbegal-Mirabent, J., Cañabate, A., \& Lebherz, P. R., (2014) "Factors influencing popularity of branded content in Facebook fan pages," European Management Journal, vol. 32, no. 6, pp. 1001-1011.

Same, S., \& Solarte-Vasquez, M. C., (2014) "Country branding and country image: insights, challenges and prospects. The case of Estonia," Baltic Journal of European Studies, vol. 4, no. 1, pp. 137-165.

Schmidt, H., \& Baumgarth, C., (2014) "Introducing a conceptual model of brand orientation within the context of Social Entrepreneurial Businesses," International Journal of Strategic Innovative Marketing, vol. 1, no. 1, pp. 37-50.

Stalidis, G., \& Karapistolis, D., (2014) Knowledge discovery and computerized reasoning to assist tourist destination marketing," International Journal of Strategic Innovative Marketing, vol. 1, no. 2, pp. 103-119.

Szopiński, T., \& Staniewski, M. W., (2016) "Socio-economic factors determining the way 
e-tourism is used in European Union member states," Internet Research, vol. 26, no. 1, pp. $2-21$.

Szymczak, H., Kücükbalaban, P., Lemanski, S., Knuth, D., \& Schmidt, S., (2016) "Trusting Facebook in crisis situations: the role of general use and general trust toward Facebook," Cyberpsychology, Behavior, and Social Networking, vol. 19, no. 1, pp. 23-27.

Tafesse, W., \& Tafesse, W., (2016) "An experiential model of consumer engagement in social media," Journal of Product \& Brand Management, vol. 25, no. 5, pp. 424-434.

Wozniak, T., Stangl, B., Schegg, R., \& Liebrich, A., (2016) "Do Social Media Investments Pay Off?: Preliminary Evidence from Swiss Destination Marketing Organizations," Information and Communication Technologies in Tourism vol. 1, no.7, pp. 267-280. 